\title{
The Effect of Knowledge Management on the Performance of Personnel of Hormozgan Payame Noor University
}

Ghanbari $\mathbf{S}^{*}$ and Dastranj $\mathbf{M}$

Department of Political Science, Payame Noor University (PNU), Tehran, Iran

*Corresponding author: Dr Ghanbari S, Assistant Professor, Department of Political Science, Payame Noor University (PNU), Tehran, Iran, Tel: +98 21 2332 0000; Email: s.ghanbari@pnu.ac.ir

Rec date: July 12th, 2017; Acc date: July 25th, 2017; Pub Date: August 10th, 2017

Copyright: (C) 2017 Ghanbari S, et al. This is an open-access article distributed under the terms of the Creative Commons Attribution License, which permits unrestricted use, distribution, and reproduction in any medium, provided the original author and source are credited.

\begin{abstract}
The purpose of the present research is to study the effect of knowledge management on personnel performance. This paper is searching the effect of component of knowledge management (create knowledge, acquisition knowledge, capture knowledge, transmission knowledge, application knowledge, organizational knowledge) on personnel performance. Population of this study were all personnel from Bandar Abbas Payame Noor University, that among a random sample of 54 personnel were selected for the study.
\end{abstract}

The research method was descriptive-survey and data collecting tool was questionnaire and knowledge management process was measured based on the five dimensions such as registration knowledge, acquisition knowledge, transfer knowledge, create knowledge, application knowledge, organizing knowledge which its validity was face validity and its reliability was established through Cronbachs alpha.

Data analysis was performed by spss software using descriptive and inferential statistics such as Pearson correlation, one-way Anova, $t$ test.

The result indicated that there was a sincere relationship between knowledge management and component of knowledge management with personnel performance. Also, there was a sincere relationship between years of service and personnel performance but no sincere relationship was observed between personnel performance and gender, education.

Keywords: Knowledge management; Personnel performance; Personnel; Payame Noor University; Hormozgan

\section{Introduction}

A large part of the activities which are related to knowledge was carried out by university which is as an educational organization. Therefore, it is necessary to clarify the status of knowledge management in higher education, and then the main component of the theory of knowledge management process should be managed for the coordination of activities related to conversion processes and the production of knowledge and thus the value of intellectual capital will be portrayed for continued active presence in human society [1]. Knowledge management as a key tool to manage the new century, in organizations, especially universities and educational establishments as provided the context for reading, creating, developing, sharing and exchange, promote the organization, maintenance and dissemination of knowledge in the educational institutions will be able to cause the formation of approach new teaching practices, effective use of existing knowledge, readiness to receive and use information and knowledge in order to develop new knowledge and technology of the third millennium, with the ability to cope with the rapidly changing world around it [2].

Knowledge management is as a scientific which supports quick and easy communication, exchange and transfer of information and can express the innovation, ability and efficiency in their organizations, especially universities [3].

Spector [4] believes that knowledge management is a new engine that can remove gaps and spaces and the educational institutions which efficient of knowledge management lead their scientific power and knowledge to more quality, innovation and performance.

Knowledge management benefits for organizations. The benefits of knowledge management in an organization is at the level of (individual and institutional); at the individual level, knowledge management enables employees to develop their skills and experience by working with others and sharing in their knowledge and learning and enhance to the professional growth. At the organizational level, knowledge management has four major benefits to an organization; Improving organizational performance through efficiency, productivity, quality and innovation, so organizations consider knowledge management as a strategic and competitive advantage [5].

By considering this issue that communities and organizations are seeking sustainable competitive advantage, so in this regard, knowledge management is a useful tool for organizations to develop their intellectual capital, encourage innovation and to maximize performance. This study seeks to answer the question of whether knowledge management has an impact on performance of personnel?

The aim of this study is to assess the level of knowledge management and whether there is a relationship between knowledge management and the performance of personnel? 


\section{Literature and theoretical foundations of this study}

Rajaeepour and Rahimi [6] in a study examine the relationship between the process of knowledge management conversion and performance of faculty members of Isfahan university. The study population consisted of 466 faculty members who were selected by using stratified random sampling and fitting with 85 persons as samples. The results show that there is a significant positive correlation the process of knowledge management conversion and performance. There is a significant difference between the average achievement of a knowledge management component of faculty members in terms of age, gender, education and employment status.

Kebria and Nazar [7] have done an article that entitled the impact of knowledge management on the research performance of the high school teachers of from the view of managers of Saghez city in the academic year 89-1388. The sample consisted of 76 male and female managers of high school. Statistical analysis showed that the current situation of knowledge management and research performance is desirable and normal in Saghez. The results showed there is a direct relationship between knowledge management and research performance of teachers, so as by enhancing knowledge management, teachers' research performance increased. Jourabchi and Khosravi [8] in a study have investigated the impact of knowledge management on the performance of girl high school's teachers in Tehran. The findings showed that if the introduction of KM initiatives of teachers is more, so increase their performance.

Davenport and Prusat [9] believe that knowledge management helps to create a culture of knowledge sharing among personnel and create value for organization by converting human capital to the organized intellectual property [9].

Specter and Anderso [4] believe that knowledge management is a new engine that can remove gaps and spaces, educational institutions efficient of knowledge management lead their scientific power and knowledge to more quality, innovation and performance.

Hulse knows the knowledge management as the process through which organizations find the ability to turn data into information and information into knowledge and will also be able to operate acquiring knowledge effectively in their decisions [10].

\section{Research Methodology}

This study used quantitative and survey techniques. Given the sample size, a questionnaire was used to collect data. The population in this study are the staffs of PNU of Hormozgan province. Sample was set up in random sampling method and with the capacity of 54 people. To collect data, a questionnaire was used with questions, statements and background. In this study to achieve the credibility assessment, validity of the questionnaire was reviewed and approved by several experts and Cronbach's alpha coefficient for each of the spectra showed that the measurement tools have high reliability. Data analysis was performed using computer software and to test the hypothesis, the bivariate analysis in Pearson correlation coefficient, ANOVA, t-test way was used. The dependent variable in this study is the performance of employees. The performance is the result of the delivery of the tasks that the organization has been responsible for human resources. In this study, the variables are in the form of questions and were assessed for Likert scale. Replies have five options ranging from very high to very low. Knowledge management is the systematic and explicit knowledge management processes that link with create, collect, organize, disseminate (transmit) and knowledge application by Skyem in 2003. For measuring the knowledge management, the knowledge management questionnaires are used which includes six dimensions of knowledge acquisition, knowledge register, knowledge transfer, knowledge create, knowledge organize and application of the knowledge.

\section{Research Hypotheses}

There is a relation between the components of KM (knowledge creation, knowledge acquisition, knowledge registration, organizing knowledge, transfer of knowledge, application of knowledge) and personnel performance:

- There is a relationship between knowledge management and personnel performance.

- There is a relationship between gender and performance.

- There is a relation between the education degree and performance.

- There is a relation between the years of service and personnel performance.

\section{Finding}

Hypothesis were measured by using t-test, regression, analysis of variance and the following results were obtained. Table 1 shows the results of regression analysis to test the relationship between knowledge management and personnel performance. Findings confirm the positive and sincere relationship between the components and performance.

\begin{tabular}{|l|l|l|l|l|l|l|l|}
\hline Components of knowledge management & $\mathbf{R}$ & $\mathbf{R 2}$ & Adj. R2 & B & Beta & Standard error & F \\
\hline Knowledge creation & $0 / 594$ & $0 / 353$ & $0 / 341$ & $1 / 049$ & $0 / 594$ & $6 / 033$ \\
\hline Knowledge acquisition & $0 / 535$ & $0 / 286$ & $0 / 272$ & $01 / 22$ & $0 / 535$ & $6 / 33$ \\
\hline Knowledge registration & $0 / 589$ & $0 / 347$ & $0 / 335$ & $0 / 969$ & $0 / 589$ & $6 / 06$ \\
\hline Organizing & $0 / 576$ & $0 / 332$ & $0 / 319$ & $1 / 15$ & $0 / 576$ & $6 / 13$ & $28 / 40$ \\
\hline Transfer of knowledge & $0 / 630$ & $0 / 397$ & $0 / 385$ & $0 / 962$ & $0 / 630$ & $5 / 82$ \\
\hline Application & $0 / 635$ & $0 / 403$ & $0 / 391$ & $1 / 35$ & $0 / 635$ & $5 / 79$ \\
\hline
\end{tabular}

Table 1: Results of regression analysis to test the relationship between the components of knowledge management and personnel performance. 
Citation: Ghanbari S and Dastranj M (2017) The Effect of Knowledge Management on the Performance of Personnel of Hormozgan Payame Noor University. J Socialomics 6: 216. doi:10.1472/2167-0358.1000216

Page 3 of 4

Table 2 shows the results of regression analysis to test the relationship between two variables, knowledge management and performance. The relationship between the two variables is confirmed. The relationship is positive, i.e., the higher use of KM results the higher level of personnel performance. The is equal to $0 / 488$ that shows knowledge management variables explain $48 / 8$ per cent of changes in personnel performance. $\mathrm{F}$ is $49 / 56$ and significant level (0/000) shows the confirming in relationship with very high confidence level.

\begin{tabular}{|l|l|l|l|l|l|l|l|l|l|}
\hline Variable & R & R2 & Adj. R2 & B & Beta & Standard error & F & T & Sig \\
\hline KM & $0 / 699$ & $0 / 488$ & $0 / 478$ & $0 / 253$ & $0 / 699$ & $5 / 36$ & $49 / 56$ & $7 / 04$ & $0 / 000$ \\
\hline
\end{tabular}

Table 2: Results of regression analysis to test the relationship between knowledge management and personnel performance.

Table 3 shows the relationship between gender and performance based on the average variance test $(\mathrm{T})$. The level of obtained statistical significance in the table ( $\operatorname{sig}=0 / 442)$, our hypothesis is not confirmed.

\begin{tabular}{|l|l|l|l|l|l|l|}
\hline Sex & Frequency & Standard deviation & Standard error & Mean & T & Sig \\
\hline Man & 26 & $6 / 04$ & $1 / 18$ & $28 / 53$ & $-0 / 775$ & $0 / 442$ \\
\hline Woman & 28 & $8 / 56$ & $1 / 61$ & $26 / 96$ & -- & -- \\
\hline
\end{tabular}

Table 3: Test results of mean difference of personnel performance by gender.

Table 4 shows the relationship between education degree and personnel performance according to the analysis of variance. Given the amount of $F(0 / 367)$ and a significance level (Sig=0/695), our

hypothesis that there is a sincere relationship between education degree and performance will not be accepted.

\begin{tabular}{|l|l|l|l|l|l|l|l|l|}
\hline Education degree & frequency & mean & Standard deviation & Standard error & Sum of square & Mean square & F & Sig \\
\hline Associate degree & 13 & $26 / 23$ & $5 / 21$ & $1 / 44$ & $41 / 53$ & $20 / 77$ & $0 / 367$ & $0 / 695$ \\
\hline BS & 28 & $28 / 39$ & $8 / 44$ & $1 / 59$ & -- & - & - & -- \\
\hline Master's degree or higher & 13 & $27 / 26$ & $7 / 27$ & $2 / 01$ & -- & - & - & - \\
\hline Total & 54 & $27 / 72$ & $7 / 43$ & $1 / 01$ & -- & - & - & - \\
\hline
\end{tabular}

Table 4: Results of the analysis of variance of personnel performance with their degree of education.

Table 5 shows the relationship between years of service of personnel and their performance by using one-way ANOVA. With respect to the
F (3/997) and obtained significant level (Sig=0/024), our hypothesis that there is a relationship between years of service and personnel performance is confirmed.

\begin{tabular}{|l|l|l|l|l|l|l|l|l|}
\hline Years of service & frequency & Mean & Standard deviation & Standard error & Sum of square & Mean of square & F & Sig \\
\hline 1 to 5 years & 23 & $26 / 95$ & $5 / 70$ & $1 / 18$ & $396 / 61$ & $198 / 30$ & $3 / 997$ & $0 / 024$ \\
\hline 6 to 10 years & 24 & $26 / 41$ & $7 / 68$ & $1 / 56$ & -- & -- & - & -- \\
\hline 11 to 15 years & 7 & $34 / 71$ & $8 / 73$ & $3 / 30$ & $1 / 01$ & -- & - & -- \\
\hline Total & 54 & $27 / 72$ & $7 / 43$ & -- & -- & - & -- \\
\hline
\end{tabular}

Table 5: Results of the analysis of variance of personnel performance with their work experience.

\section{Discussion and Conclusion}

The use of knowledge management is an integral part of the university and using it increases the level of knowledge and scientific information in an educational system. Appropriate and effective organizational culture that supports exchange and transfer of knowledge between distinct levels of the organization, so that people without any fear give their information and knowledge to their colleagues. If the sharing of knowledge be higher by personnel, thereby the performance of them increase. This study aims to investigate and explain the personnel performance of PNU of Hormozgan province. To this end, by using studies and theoretical variables were developed to measure their impact on personnel performance. To achieve this goal, the assumptions were derived and purpose of the research was to 
Citation: Ghanbari S and Dastranj M (2017) The Effect of Knowledge Management on the Performance of Personnel of Hormozgan Payame Noor University. J Socialomics 6: 216. doi:10.1472/2167-0358.1000216

Page 4 of 4

test this hypothesis. The variables are in the form of a bunch of questions and by a questionnaire, was given to the subjects and finally data obtained from a sample of 54 people. The results showed that the respondents in all aspects of knowledge management: knowledge creation, knowledge acquisition, knowledge, organize knowledge, transfer of knowledge, application of knowledge is moderate to high. Overall, the findings suggest that, knowledge management and its dimensions are significantly associated with performance and direct and positive relationship is dominated between. Thus, if the personnel achieving to the components of knowledge management increase, so their performance increase. Regarding the relationship between knowledge management and performance in research, teaching and learning of human resources to develop efficient, competent and proficient in science, provides the foundation and success of any organization. Therefore, knowledge management is not an exception. Efficiency and high capacity of human resources in any organization will allow the organization in compared to the environmental changes show the necessary flexibility and by leadership them achieve major abilities.

\section{References}

1. Rawley J (2000) Is higher education ready for knowledge management. Int J Educ Manag 14: 325-333.
2. Saied JM (2004) Knowledge management in school-based management system. J Edu 18.

3. Almolok IA (2006) Studies of knowledge management in the higher education system and provide convenient, thesis PHD, educational administration. Islamic Azad University, Science and Research, Iran.

4. Spector JM, Anderson TM (2000) Integrated and holistic domains. Dordrecht: Kluwer Academic, Netherlands.

5. Naser S, Mohammadreze D (2006) Knowledge management in organizations. Tehran: Arad books publication.

6. Saied R, Rahimi H (2009) The relationship between the process of knowledge management and performance of faculty members of Isfahan university. Journal of Humanities and Social Sciences Management 4: 59-76.

7. Baharak SK, Hossein K (2010) The impact of knowledge management on the performance of the high school teachers in view of managers in the academic year 89-1388 of Saghez city. J Educ Admin 2: 11-36.

8. Mahnaz J, Akbar KA (2010) The impact of knowledge management on the performance of teachers in secondary schools in Tehran. Quarterly new ideas in education 5 .

9. Danport E, Prosatt B (2009) The role of knowledge management in universities goals.

10. Hossein AS, Adel S (2007) Knowledge management in organization. Tehran, Payvand Noo Publication, (1st edn). 